\title{
Development of Nested PCR Primer Set for the Specific and Highly Sensitive Detection of Human Parvovirus B19
}

\author{
Kyu-Bong Cho ${ }^{\dagger}$ ** \\ Department of Biomedical Laboratory Science, Shinhan University, Uijeongbu 11644, Korea
}

\begin{abstract}
For the specific detection of human Parvovirus B19 (HuPaV-B19), we designed ten specific PCR primers from 3,800 4,500 nucleotides of HuPaV-B19 complete genome (NC_000883.2). Seventeen candidate PCR primer sets for specific detecting HuPaV-B19 were constructed. In specific reaction of HuPaV-B19, seventeen PCR primer sets showed specific band, however five PCR primer sets were selected basis of band intensity, amplicon size and location. In nonspecific reaction with seven reference viruses, four PCR primer sets showed non-specific band, however one PCR primer set is not. Detection sensitivity of final selective PCR primer set was $100 \mathrm{fg} / \mu \mathrm{L}$ for 112 minute, and PCR amplicon is 539 base pairs (bp). In addition, nested PCR primer set was developed, for detection HuPaV-B19 from a low concentration of contaminated samples. Selection of nested PCR primer set was basis of sensitivity and groundwater sample tests. Detection sensitivity of final selective PCR and nested PCR primer sets for the detection of HuPaV-B19 were $100 \mathrm{fg} / \mu \mathrm{L}$ and $100 \mathrm{ag} /$ $\mu \mathrm{L}$ basis of HuPaV-B19 plasmid, it was able to rapid and highly sensitive detection of HuPaV-B19 than previous reports. We expect developed PCR primer set in this study will used for detection of HuPaV-B19 in various samples.
\end{abstract}

Key Words: Human Parvovirus B19, Polymerase chain reaction, Nested PCR

\section{서 론}

사람 파보바이러스 B19 (human Parvovirus B19; HuPaVB19)는 group II ssDNA virus, Parvoviridae, Erythroparvovirus 로 분류되며(Heegaard and Brown, 2002), 소아 전염성 홍반 및 성인 류마티스성 관절염 등의 증상이 나타난다(White et al., 1985). 일반적으로는 호흡기를 통해 감염되는 것으 로 알려져 있었으나, 수혈, 장기 이식 등 임상적 감염 사 례뿐만 아니라 음용수에서 오염이 보고된 바 있다(Casteel et al., 2002; Schmidt et al., 2007; Marano et al., 2015). 최근 $\mathrm{HuPaV}-\mathrm{B} 19$ 를 진단하기 위한 방법으로 중합효소연쇄반응 (polymerase chain reaction; PCR)을 기반으로 한 특이적 핵
산 단편 증폭이 활용되고 있다(Bonvicini et al., 2009; Bock et al., 2014). PCR 방법 중 conventional PCR은 많은 연구로 안정성이 검증되었고, 분석자의 넓은 활용층을 가지고 있 으며, 임상 및 비 임상 시료에서 활용할 수 있어 표준화 방법으로 적합하다(Park et al., 2016; Cho, 2018). 그러나 다수 의 연구자들에 의해 HuPaV-B19를 진단하는 conventional PCR primer 조합이 보고(Sevall et al., 1992; Bergallo et al., 2008; Bonvicini et al., 2009; Bock et al., 2014)되고 있고, 특이 성, 검출 민감도, 반응 시간, 비용 등의 비교 연구가 미흡 하다. 한편, 음용수에서 $\mathrm{HuPaV}-\mathrm{B} 19$ 가 검출에 따라 임상 외 시료에서도 모니터링이 필요하다. 그러나 음용수 등 물 환경은 임상 시료들에 비해 상대적으로 바이러스가 미량 오염될 가능성이 크기 때문에 높은 검출 민감도가 요구된

Received: November 19, 2018 / Revised: December 8, 2018 / Accepted: December 13, 2018

*Professor

${ }^{\dagger}$ Corresponding author: Kyu-Bong Cho. Department of Biomedical Laboratory Science, Shinhan University, 95, Hoam-ro, Uijeongbu-si, Gyeonggi-do 11644, Korea.

Tel: +82-31-870-3712, Fax: +82-31-870-3719, e-mail: kbcho@ shinhan.ac.kr

(C)The Korean Society for Biomedical Laboratory Sciences. All rights reserved.

@ This is an Open Access article distributed under the terms of the Creative Commons Attribution Non-Commercial License (http://creativecommons.org/licenses/by-nc/3.0/) which permits unrestricted non-commercial use, distribution, and reproduction in any medium, provided the original work is properly cited. 


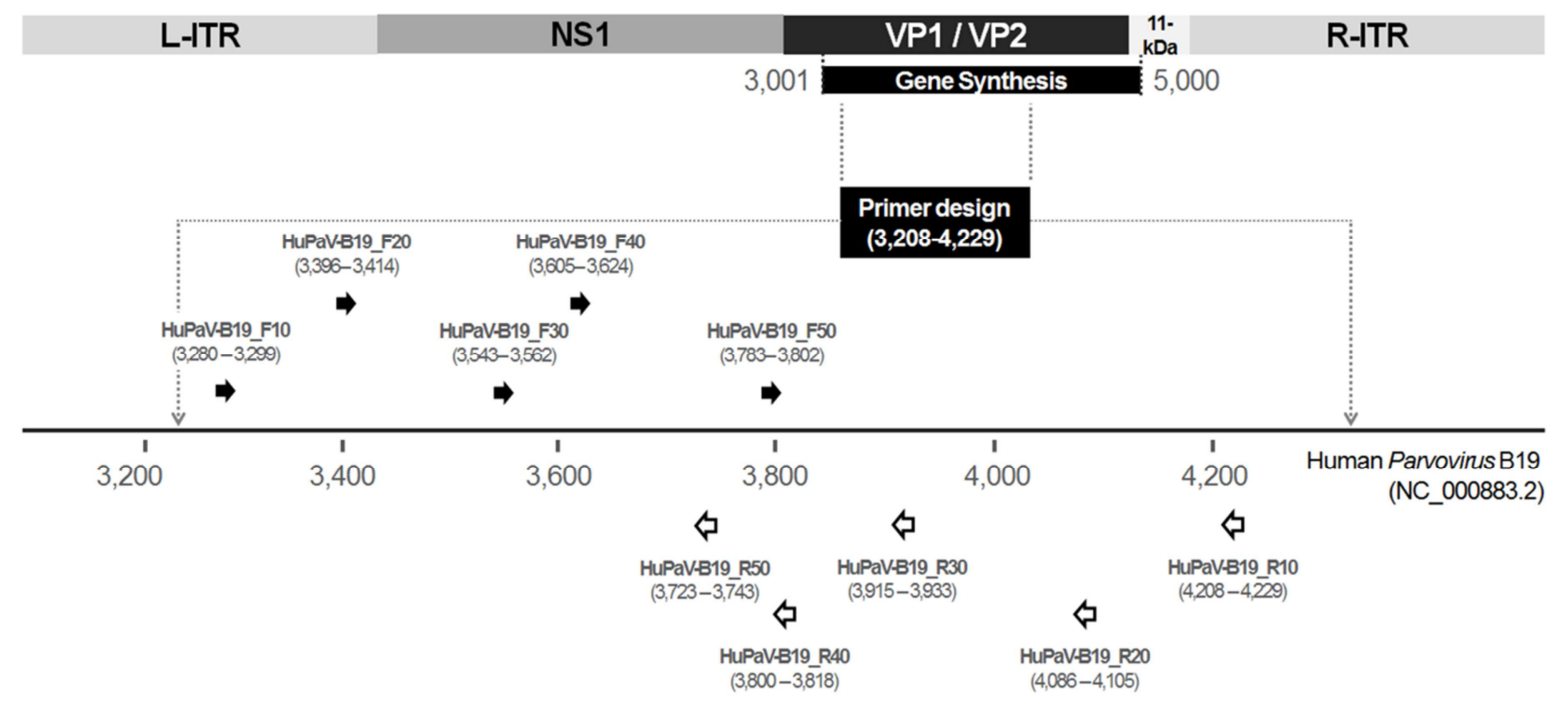

Fig. 1. Map of specific PCR primers for the detection of human Parvovius B19.

다(Cho, 2018). 또한 임상과 비 임상 등 시료 별로 활용하 는 PCR 조건 및 HuPaV-B19 핵산이 증폭되는 위치가 달 라서 유전형 연구, 시료 별 연계 연구 등에 어려움이 따른 다. 따라서 본 연구에서는 HuPaV-B19 특이적 진단이 가 능한 PCR primer 조합 및 높은 검출 민감도로 검출할 수 있는 nested PCR primer 조합을 개발하였으며, 기존에 보고 된 HuPaV-B19 conventional PCR primer 조합들과 비교하였 다. 또한 최종 선발한 PCR 및 nested PCR primer 조합의 시료 적용성 연구를 수행하였다.

\section{재료 및 방법}

\section{PCR primer 설계}

미국 국립생물정보센터에서 HuPaV-B19 complete genome (NC_000883.2) 염기서열을 수집하였으며, 이 중 구조 단 백질을 코딩하는 HuPaV-B19 VP1와 VP2 gene을 대상으로 하였다. DNAMAN software package version 6.0 (Lynnon Biosoft, Quebec, Canada)로 특이적 primer 설계 후 Oligo Calculator version 3.27로 potential hairpin formation 등의 여 부를 확인하였으며(Kibbe, 2007), 총 10개의 primer들을 제 작하였다(Fig. 1).

\section{바이러스 핵산 수집}

HuPaV-B19 (NC_000883.2)의 VP1 및 VP2 구간 2,000 nucleotides $(3,001 \sim 5,000)$ 를 합성하여 plasmid화 하였으며,
비 특이적 실험에 활용한 7종의 참고 바이러스(human enteric Adenovirus-41, Aichivirus A, human Astorivirus, Parechovirus A, Poliovirus 및 Sapovirus)의 핵산을 수집하였다.

\section{$\mathrm{PCR}$ 및 nested PCR primer 선발}

HuPaV-B19 특이적 primer 10개를 기초로 PCR 증폭이 가능한 17 개 $\mathrm{PCR}$ 조합을 구성하였다(Table 1). 구성한 조 합에서 HuPaV-B19 핵산에 특이적 및 참고 바이러스에 비 특이적 반응을 검정하였다. 특이적 반응만 나타난 $\mathrm{PCR}$ primer 조합들의 검출 민감도 분석은 HuPaV-B19 plasmid 를 $1 \mathrm{ng} / \mu \mathrm{L}$ 를 원액으로 $10^{-8}(10 \mathrm{ag} / \mu \mathrm{L})$ 까지 10 배 단계 희석 하여 반응을 분석 후 최종 하나의 조합을 선발하였다. 또 한 검출 민감도 시험을 통해 nested PCR 1개의 primer 조 합을 선발하였다. PCR 조성은 AccuPower ${ }^{\circledR}$ HotStart PCR PreMix (Bioneer, Korea), 정방향 및 역방향 프라이머 (25 pmol) 각 $1 \mu \mathrm{L}$ (총 $2 \mu \mathrm{L}$ ), 주형 핵산 $1 \mu \mathrm{L}$ 및 nucleic acid free water $17 \mu \mathrm{L}$ 로 최종 $20 \mu \mathrm{L}$ 로 하였으며, 조건은 $95^{\circ} \mathrm{C}$ 에 서 10 분간 변성 후, 35 회 반복 $\left(95^{\circ} \mathrm{C} 45\right.$ 초, $55^{\circ} \mathrm{C} 1$ 분 및 $72^{\circ} \mathrm{C}$ 1 분) 후 $72^{\circ} \mathrm{C} 5$ 분 간 반응하였다. PCR 산물은 $1.2 \%$ agarose gel에 로딩 후 $100 \mathrm{~V}$ 에서 30 분 동안 전기영동 하였으며, UV illuminator에서 결과를 확인하였다.

\section{기존 실험 비교}

현재까지 보고된 HuPaV-B19 진단용 conventional PCR primer 조합(Yamakawa et al., 1995; Cassinotti et al., 1993; 
Table 1. PCR and nested PCR primer sets for the detection of HuPaV-B19

\begin{tabular}{|c|c|c|c|c|c|c|}
\hline $\begin{array}{l}\text { Primer } \\
\text { set }\end{array}$ & $\begin{array}{l}\text { PCR } \\
\text { type }\end{array}$ & $\begin{array}{l}\text { Primer } \\
\text { name }\end{array}$ & Sequences $\left(5^{\prime} \rightarrow 3^{\prime}\right)$ & $\begin{array}{l}\text { Amplicon } \\
\text { size (bp) }\end{array}$ & $\begin{array}{l}\text { Sequence } \\
\text { location }\end{array}$ & Reference \\
\hline $1 \sim 17$ & $\begin{array}{l}\text { PCR and } \\
\text { nested PCR }\end{array}$ & & $-{ }^{*}$ & $323 \sim 834$ & $3,280 \sim 4,229$ & $\begin{array}{l}\text { This } \\
\text { study }\end{array}$ \\
\hline \multirow{4}{*}{ Ref. 01} & \multirow{2}{*}{ PCR } & TJI & TTCTTTTCAGCTTTTAGG & \multirow{2}{*}{200} & $3,775 \sim 3,792$ & \multirow{4}{*}{ [8] } \\
\hline & & TJII & GTACTTCTGGTACGTTAAGT & & $3,956 \sim 3,975$ & \\
\hline & \multirow{2}{*}{$\begin{array}{l}\text { Nested } \\
\text { PCR }\end{array}$} & 968 & TATAAGTTTCCTCCAGTGCC & \multirow{2}{*}{120} & $3,818 \sim 3,837$ & \\
\hline & & $967 b$ & TGTAATCCTCCACTGGGTT & & $3,920 \sim 3,938$ & \\
\hline \multirow{4}{*}{ Ref. 02} & \multirow{2}{*}{ PCR } & $\mathrm{F} 1$ & TATGCTTACTTAACAGTAGG & \multirow{2}{*}{852} & $3,566 \sim 3,585$ & \multirow{4}{*}{ [14] } \\
\hline & & $\mathrm{R} 1$ & AATTGGCCCACTTTGTGG & & $4,417 \sim 4,400$ & \\
\hline & \multirow{2}{*}{$\begin{array}{l}\text { Nested } \\
\text { PCR }\end{array}$} & $\mathrm{F} 2$ & GCCTTAGCACAGGTACCTCT & \multirow{2}{*}{397} & $3,960 \sim 3,979$ & \\
\hline & & $\mathrm{R} 2$ & САTCCTCCTAAGGCTGCAAAC & & $4,234 \sim 4,253$ & \\
\hline \multirow{4}{*}{ Ref. 03} & \multirow{2}{*}{ PCR } & $1^{\text {st }}$ Forward & CAAAAGCATGTGGAGTGAGG & \multirow{2}{*}{398} & $3,187 \sim 3,206$ & \multirow{4}{*}{ [7] } \\
\hline & & $1^{\mathrm{st}}$ Reverse & CTACTAACATGCATAGGCGC & & $3,584 \sim 3,565$ & \\
\hline & \multirow{2}{*}{$\begin{array}{l}\text { Nested } \\
\text { PCR }\end{array}$} & $2^{\text {nd }}$ Forward & CCCAGAGCACCATTATAAGG & \multirow{2}{*}{288} & $3,271 \sim 3,290$ & \\
\hline & & $2^{\text {nd }}$ Reverse & GTGCTGTCAGTAACCTGTAC & & $3,558 \sim 3,539$ & \\
\hline \multirow{4}{*}{ Ref. 04} & \multirow{2}{*}{ PCR } & Vp2i-Forward & CTAGAATATCCTTACGCCCTGG & \multirow{2}{*}{386} & $4,274 \sim 4,295$ & \multirow{4}{*}[16]{} \\
\hline & & Vp2i-Reverse & GTGGCTGATGCAAACCCCATC & & $4,660 \sim 4,640$ & \\
\hline & \multirow{2}{*}{$\begin{array}{l}\text { Nested } \\
\text { PCR }\end{array}$} & Vp2p-Forward & CCATTTCTCATGGTCAGACCAC & \multirow{2}{*}{193} & $4,355 \sim 4,376$ & \\
\hline & & Vp2p-Reverse & CCATACAGAACCCACCATTAGG & & $4,548 \sim 4,527$ & \\
\hline \multirow{2}{*}{ Ref. 05} & \multirow{2}{*}{ PCR } & Primer A & AGCATGACTTCAGTTAATTC & \multirow{2}{*}{727} & $3,122 \sim 3,141$ & \multirow{2}{*}{ [17] } \\
\hline & & Primer B & GATTGTACATTTCATAAAAG & & $3,868 \sim 3,887$ & \\
\hline \multirow{4}{*}{ Ref. 06} & \multirow{2}{*}{ PCR } & $1^{\mathrm{ST}}$ Forward & AGCATGTGGAGTGAGGGGGC & \multirow{2}{*}{290} & \multirow{4}{*}{ No Data } & \multirow{4}{*}{ [9] } \\
\hline & & $1^{\mathrm{ST}}$ Reverse & AAAGCATCAGGAGCTATACTTCC & & & \\
\hline & Nested & $2^{\mathrm{ND}}$ Forward & GCTAACTCTGTAACTTGTAC & \multirow{2}{*}{173} & & \\
\hline & PCR & $2^{\mathrm{ND}}$ Reverse & AAATATCTCCATGGGGTTGAG & & & \\
\hline
\end{tabular}

${ }^{*}$ Sequences of final selective PCR primer were shown in Table 3

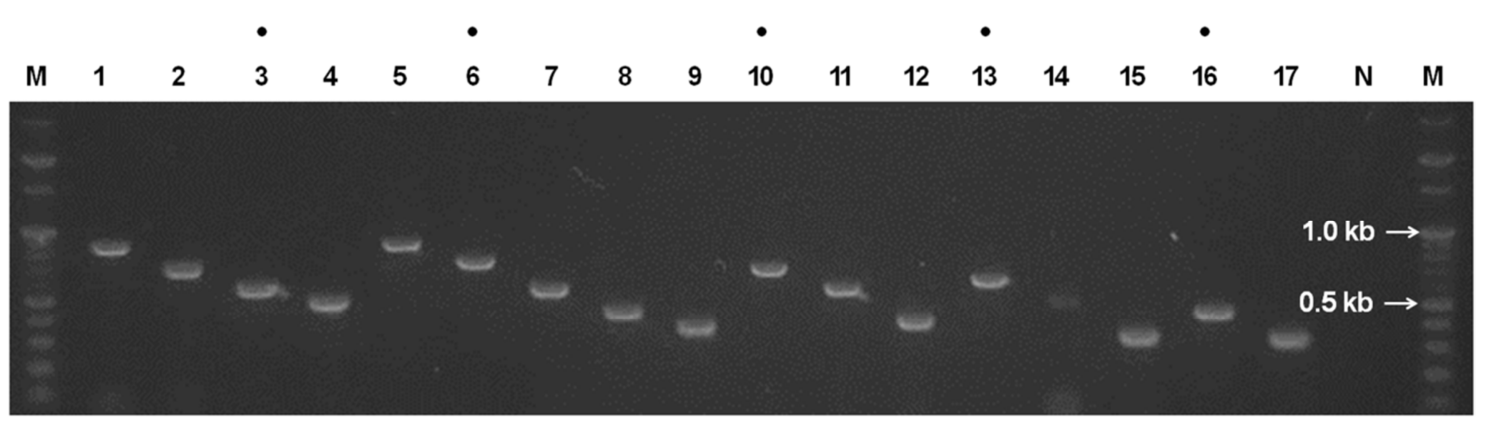

Fig. 2. Specific reaction of seventeen PCR primer sets for detection of HuPaV-B19. M, 100 bp Ladder marker (MGMed, Korea); lane number, number of PCR primer set (\#01 17); N, negative control; dot, selective PCR primer set.

Bergallo et al., 2008; Bock et al., 2014)들과 이번 연구에서 개발한 방법의 검출 민감도, 반응 시간, 시료 적용성 등을 비교하였다(Table 1). 검출 민감도 비교는 HuPaV-B19 plas- mid 단계 희석액을 사용하였고, 반응 시간은 $\mathrm{PCR}$ 이 반응 하는데 걸리는 시간으로 하였다. 

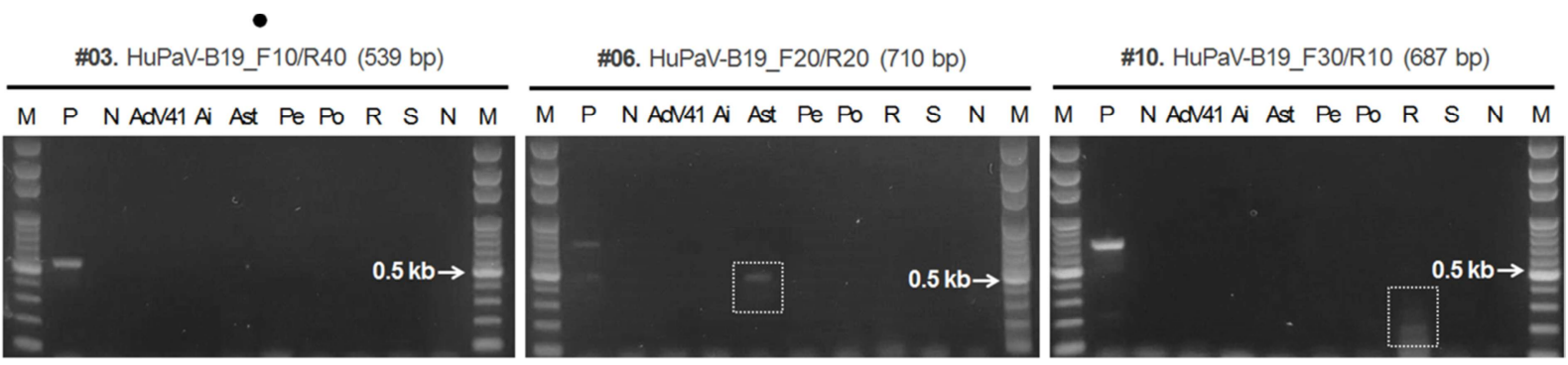

\#13. HuPaV-B19_F40/R10 (625 bp)

\#16. HuPaV-B19_F50/R10 (447 bp)
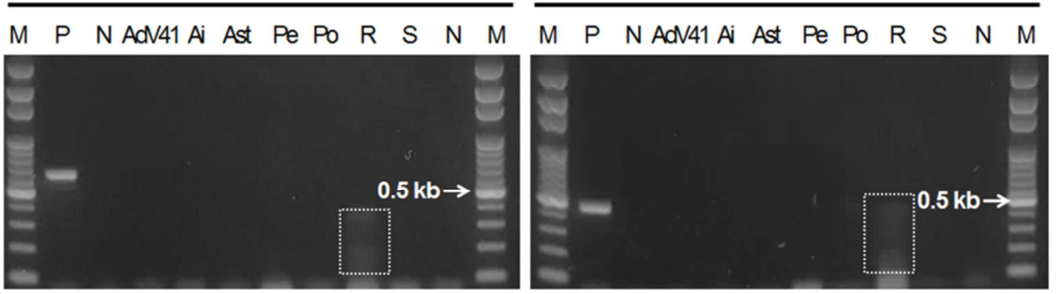

Fig. 3. Non-specific reaction of five primer sets basis of seven refernece viruses. Lane M, 100 bp Ladder marker; P, positive control; N, negative control; AdV41, human Adenovirus 41; Ai, Aichivirus; Ast, Astrovirus; Pe, Parechovirus A; Po, Poliovirus; S, Sapovirus; N, Norovirus GII; dot, selective PCR primer sets.

\section{시료 적용성 시험}

시료 적용성 분석을 위하여 20 개의 지하수 시료를 임의 로 채취하였으며, 탈리 및 농축 후 DNeasy ${ }^{\circledR}$ PowerWater ${ }^{\circledR}$ Kit (Qiagen, Germany)로 총 핵산을 추출하였다. 본 연구에 서 개발한 PCR 및 nested PCR primer 조합을 활용하여 지 하수에서 추출한 총 핵산을 주형으로 HuPaV-B19를 진단 하였다.

\section{결 과}

\section{PCR 및 nested PCR primer 선발}

HuPaV-B19 특이적 PCR primer 17개 조합에서 모두 특 이적 밴드가 나타났다. 이 중 밴드의 증폭 정도, 크기, 위 치 등을 고려하여 5개의 PCR primer 조합(\#03, \#06, \#10, \#13 및 \#16)을 선발하였다(Fig. 2). 선발한 PCR primer 조합 5 개 중 4개(\#06, \#10, \#13 및 \#16) 조합에서 참고 바이러스 핵산에 비 특이적 반응이 나타났으며, 1 개(\#03) 조합은 비 특이적 반응이 나타나지 않았다(Fig. 3). PCR primer 조합 \#03은 539 base pairs (bp) 크기의 HuPaV-B19 핵산 단편을 특이적으로 증폭하였으며, 검출 감도는 $100 \mathrm{fg} / \mu \mathrm{L}$ 까지로 분석되었다(Fig. 4). PCR primer 조합 \#03이 증폭한 핵산 단 편 $539 \mathrm{bp}$ 에서 증폭이 가능한 3개의 ested PCR primer 조합 을 설계하였다. 검출 민감도 분석 결과 $1 \mathrm{fg} / \mu \mathrm{L} \sim 100 \mathrm{ag} / \mu \mathrm{L}$

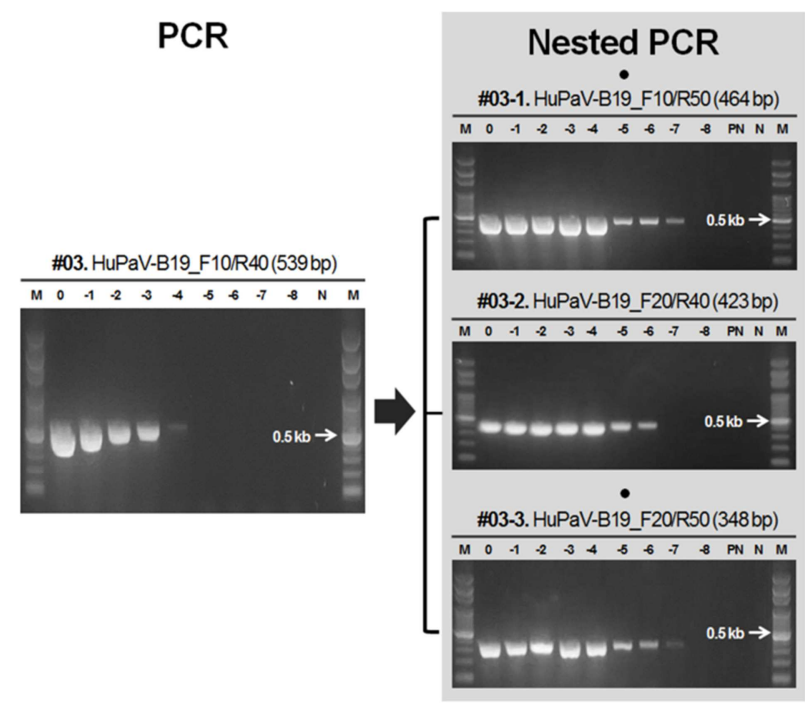

Fig. 4. Sensitivity of PCR and candidate nested PCR primer sets. Lane M, 100 bp Ladder marker; lane number, dilution rates; N, negative control; PN, PCR negative control.

수준으로 HuPaV-B19 특이적 핵산 단편을 증폭할 수 있었 으며, 이 중 높은 검출 민감도가 나타난 2개의 후보 nested PCR primer 조합을 선발하였다(Fig. 4). 


\section{기존 조건 비교}

HuPaV-B19 검출용 conventional PCR primer 조합 6개를 대상으로 검출 민감도를 분석한 결과 한 번의 $\mathrm{PCR}$ 에서는 $1 \mathrm{ng} / \mu \mathrm{L}$ 이하에서 $100 \mathrm{fg} / \mu \mathrm{L}$ 수준이었으며, nested PCR 결과 $1 \mathrm{ng} / \mu \mathrm{L}$ 에서 $10 \mathrm{fg} / \mu \mathrm{L}$ 수준으로 나타났다(Table 2). 한 번의 $\mathrm{PCR}$ 에서 검출 민감도가 높았던 조합은 비교 primer 5 번으 로 반응 시간이 130 분이었으며, nested PCR 검출 민감도가 가장 높았던 비교 primer 조합은 3번과 6번으로 PCR 시 간을 포함하여 각각 380 분과 136 분이었다. 이번 연구에서 개발한 PCR primer 조합은 비교 primer 5 번과 동일 수준의 검출 민감도가 나타났으나 반응 시간을 약 18 분 단축하였 다. 또한 nested PCR primer 조합은 반응 시간이 총 224분 으로 비교 primer 6 번에 비해 88 분 반응 시간이 길었으나

Table 2. Comparison of performance between this study and previously reported $\mathrm{PCR}$ primer sets

\begin{tabular}{|c|c|c|c|}
\hline \multicolumn{2}{|c|}{ Primer set } & \multirow{2}{*}{$\begin{array}{c}\begin{array}{c}\text { Reaction time } \\
(\mathrm{min})\end{array} \\
112\end{array}$} & \multirow{2}{*}{$\begin{array}{c}\text { Sensitivity } \\
100 \text { femto gram }\end{array}$} \\
\hline This tu & PCR & & \\
\hline InIs study & Nested PCR ${ }^{*}$ & 224 & 100 atto gram \\
\hline \multirow{2}{*}{$\begin{array}{l}\text { Ref. primer } \\
\text { set } 1\end{array}$} & PCR & 220 & $>1$ nano gram \\
\hline & Nested PCR ${ }^{*}$ & 440 & 10 pico gram \\
\hline \multirow{2}{*}{$\begin{array}{l}\text { Ref. primer } \\
\text { set } 2\end{array}$} & PCR & 86 & 10 pico gram \\
\hline & Nested PCR ${ }^{*}$ & 131 & 100 femto gram \\
\hline \multirow{2}{*}{$\begin{array}{l}\text { Ref. primer } \\
\text { set } 3\end{array}$} & PCR & 190 & 100 pico gram \\
\hline & Nested PCR ${ }^{*}$ & 380 & 10 femto gram \\
\hline \multirow{2}{*}{$\begin{array}{l}\text { Ref. primer } \\
\text { set } 4\end{array}$} & PCR & 130 & 1 pico gram \\
\hline & Nested PCR ${ }^{*}$ & 220 & 1 pico gram \\
\hline $\begin{array}{l}\text { Ref. primer } \\
\text { set } 5\end{array}$ & PCR & 230 & 1 pico gram \\
\hline \multirow{2}{*}{$\begin{array}{l}\text { Ref. primer } \\
\text { set } 6\end{array}$} & PCR & 68 & 100 pico gram \\
\hline & Nested PCR & 136 & 10 femto gram \\
\hline
\end{tabular}

*Reaction time of nested PCR is the sum of PCR and nested PCR reaction times
약 100 배 이상의 검출 민감도가 나타났다(Table 2).

\section{시료 적용성 시험}

본 연구에서 개발한 PCR primer 조합 및 후보 nested PCR primer 조합 2개를 대상으로 시료 적용성 시험을 수 행하였다. PCR 수준에서는 20개 시료 모두 HuPaV-B19 음 성으로 나타났으나, nested PCR primer 조합 중 최종 산물 $464 \mathrm{bp}$ 를 증폭하는 조합에서 HuPaV-B19 특이적 밴드가 나타나(Fig. 5) 최종 nested PCR primer 조합으로 선발하였 다. 최종 선발한 PCR 및 nested PCR primer 조합의 정보는 Table 3과 같다.

\section{고 찰}

본 연구에서는 HuPaV-B19 진단용 PCR 및 nested PCR primer 조합을 개발하였다. HuPaV-B19를 진단할 수 있는 분석법은 PCR 방법 외 효소면역분석법, 닷블랏혼성화법 등이 활용될 수 있다(Schwarz et al., 1988; Mori et al., 1989; Brown et al., 1990; Gray et al., 1993; Bostic et al., 1999). 그러 나 특이성, 검출 민감도, 분석 난이도, 검사자의 위험성, 비 용 등을 종합적으로 고려하여 핵산 단편을 증폭하는 기 술이 증가하고 있는 추세이다(Cho, 2018). 핵산 단편 증 폭 기반의 방법 중 real-time qPCR은 특이성과 검출 민감 도가 높고 신속하게 진단이 가능하여 많은 활용이 보고 (Sewell, 1995)되고 있으나 염기서열 분석을 할 수 없어 유 전형 분석이 어렵고, 결과 분석 등 conventional PCR에 비 해 검사자의 숙련도가 필요한 단점이 있다. 또한 등온증 폭법(loop-mediated isothermal amplification)은 비 특이적 위 양성 반응이 많이 나타나고 비용이 비싼 단점이 보고되고 있다(Smith and Osborn, 2009). 이에 비해 conventional PCR 은 염기서열 분석이 가능하고 위 양성 반응이 상대적으로 낮게 나타나므로 표준 분석기술로 적합하다고 사료된다.

한편, 음용수 등에서도 HuPaV-B19가 검출되면서(Casteel et al., 2002), 향 후 임상 외 음용수를 포함한 식품, 어패류,

Table 3. Information of finally selective PCR and nested PCR primer set for the detection of HuPaV-B19

\begin{tabular}{lllcc}
\hline \hline PCR tpye & \multicolumn{1}{c}{ Primer } & \multicolumn{1}{c}{ Sequence $\left(5^{\prime} \rightarrow 3^{\prime}\right)$} & Mer $(\mathrm{nt})$ & Amplicon size $(\mathrm{bp})$ \\
\hline \multirow{2}{*}{ PCR } & HuPaV-B19_F10 & CAACGCCTCAGAAAAATACC & 20 & \multirow{2}{*}{539} \\
& HuPaV-B19_R40 & GGGCTAAAGTATCTTGACC & 19 & \multirow{2}{*}{464} \\
\multirow{2}{*}{ Nested PCR } & HuPaV-B19_F10 & CAACGCCTCAGAAAAATACC & 20 & 22 \\
& HuPaV-B19_R10 & CTCCAGTATTAGAGCTGTCTCC & 22 & \\
\hline
\end{tabular}



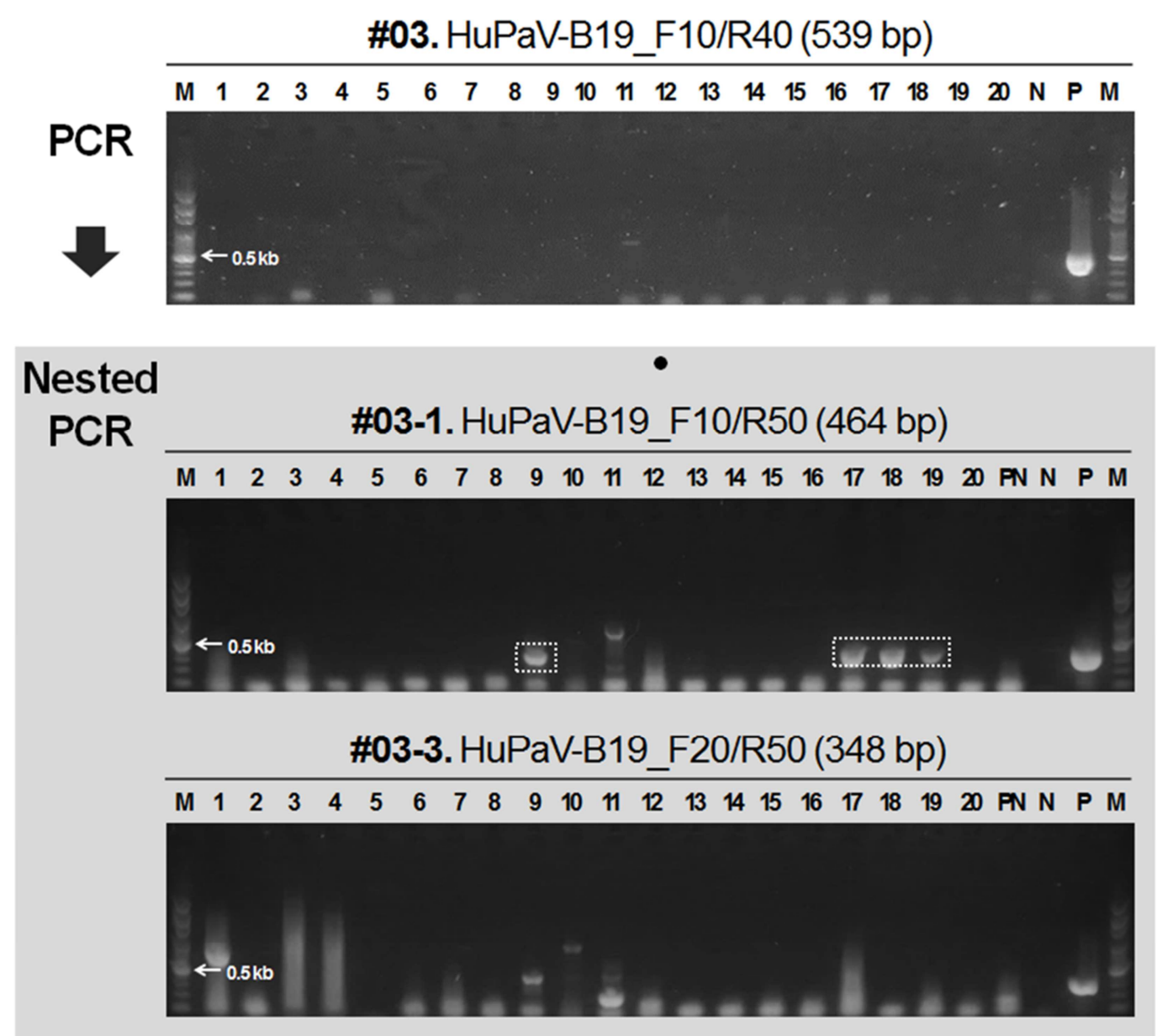

Fig. 5. Test of twenty groundwater samples using the final selective PCR primer set and candidate two nested PCR primer sets. Lane M, 100 bp Ladder marker; Lane 1 20, groundwater sample; N, negative control; PN, PCR negative control; dot, selective nested PCR primer sets.

환경 시료 등에서도 HuPaV-B19 모니터링이 필요할 것으 로 보인다. 최근 국내 범부처 수인성·식품매개 바이러스 협의체에서 Norovirus $\mathrm{GI}$ 과 $\mathrm{GI}$ 를 검사하는 표준화 방법으 로 conventional PCR을 채택 및 추진하고 있다(Park et al., 2016). 이에 따라 다양한 시료에서 병원체의 검사를 수행 해야 하는 검사법 개발은 연구의 연관성, 검사자의 편리성 등이 고려되어야 한다. 특히 물 환경과 같이 바이러스의 극미량 오염이 예상되는 시료에서는 nested PCR 이상의 검출 감도가 필요하다(Kittigul et al., 2005; Cho, 2018). 이번 연구에서 개발한 PCR primer 조합은 약 112 분 반응으로 $\mathrm{HuPaV}-\mathrm{B} 19$ 를 특이적으로 증폭하였으며 산물은 $539 \mathrm{bp}$ 였 다. PCR primer 조합은 기존에 보고된 6 개의 조합 중 가장 검출 민감도가 높은 조합과 동등 수준이었으나 반응 시간 을 약 18 분 단축시켰다. PCR primer 조합은 고 농도 감염
또는 오염이 예상되는 임상, 식품, 어패류 등의 시료 검사 에 적합할 것으로 생각된다. 또한 nested PCR primer 조합 은 약 112 분의 추가 반응으로 $100 \mathrm{ag} / \mu \mathrm{L}$ 수준까지 검출할 수 있었다. 이것은 기존에 보고된 PCR primer 조합들 보 다 검출 민감도를 약 100 배 수준으로 향상시킬 수 있었으 며, 지하수 시료에서도 진단이 가능한 것이 확인되었다. Nested PCR primer 조합은 미량 오염이 예상되는 환경 시 료에서의 활용이 적합 할 것으로 보인다.

본 연구에서 개발한 PCR 및 nested PCR primer 조합 은 기존 연구에 비해 빠른 반응 및 높은 검출 민감도로 HuPaV-B19를 검출할 수 있었다. 이번 연구는 향후 임상 및 비 임상 시료 등에서 HuPaV-B19를 진단하는 방법으로 활용할 수 있을 것으로 기대된다. 


\section{ACKNOWLEDGEMENT}

본 논문은 2018년도 신한대학교 학술연구비 지원으로 연구되었음.

\section{CONFLICT OF INTEREST}

No potential conflict of interest relevant to this article was reported.

\section{REFERENCES}

Bergallo M, Costa C, Sidoti F, Novelli M, Ponti R, Castagnoli C, et al. Variants of Parvovirus B19: bioinformatical evaluation of nested PCR assays. Intervirology. 2008. 51: 75-80.

Bock CT, Duchting A, Utta F, Brunner E, Sy BT, Klingel K, et al. Molecular phenotypes of human parvovirus B19 in patients with myocarditis. World J Cardiol. 2014. 26: 183-195.

Bonvicini F, Manaresi E, Gallinella G, Gentilomi GA, Musiani M, Zerbini M. Diagnosis of fetal parvovirus B19 infection: value of virological assays in fetal specimens. BJOG. 2009. 116: 813-817.

Bostic JR, Brown KE, Young NS, Koenig S. Quantitative analysis of neutralizing immune responses to human parvovirus B19 using a novel reverse transcriptase-polymerase chain reactionbased assay. J Infect Dis. 1999. 179: 619-626.

Brown CS, van Bussel MJ, Wassenaar AL, van Elsacker-Niele AM, Weiland HT, Salimans MM. An immunofluorescence assay for the detection of parvovirus B19 $\mathrm{IgG}$ and IgM antibodies based on recombinant viral antigen. J Virol Methods. 1990. 29: 53-62.

Cassinotti P, Weitz M, Siegl G. Human Parvovirus B19 infections: routine diagnosis by a new nested polymerase chain reaction assay. J Med Virol. 1993. 40: 228-234.

Casteel MJ, Gold A, Sobsey MD, Brecher ME. Photosensitization of hepatitis A virus and other non-enveloped RNA viruses by mesosubstituted porphyrins in water and human plasma. (Holick M.F. Eds). 2002. Biologic Effects of Light 2001. Boston, MA.

Cho KB. Construction of Improved PCR Primer Set for the Detection of Human Enteric Adenovirus 41. Biomedical Science Letters. 2018. 24: 230-238.

Gray JJ, Cohen BJ, Desselberger U. Detection of human parvovirus B19-specific IgM and $\operatorname{IgG}$ antibodies using a recombinant viral VP1 antigen expressed in insect cells and estimation of time of infection by testing for antibody avidity. J Virol Methods.
Heegaard ED, Brown KE. Human parvovirus B19. Clin Microbiol Rev. 2002. 15: 485-505.

Kibbe WA. OligoCalc: an online oligonucleotide properties calculator. Nucleic Acids Res. 2007. 35: 43-46.

Kittigul L, Ekchaloemkiet S, Utrarachkij F, Siripanichgon K, Sujirarat D, Pungchitton S, et al. An efficient virus concentration method and RT-nested PCR for detection of rotaviruses in environmental water samples. J Virol Methods. 2005. 124: 117-122.

Marano G, Vaglio S, Pupella S, Facco G, Callizzani G, Candura F, et al. Human parvovirus B19 and blood product safety: a tale of twenty years of improvements. Blood Transfus. 2015. 13: 184-186.

Mori J, Field AM, Clewley JP, Cohen BJ. Dot blot hybridization assay of B19 virus DNA in clinical specimens. J Clin Microbiol. 1989. 27: 459-464.

Park S, Lee S, Chung H, Park J, Park S, et al., Development and verification of genetically diagnostic method for the detection of non-regulated viruses from water environment (I). National Institute of Environmental Research; 2016 Dec. p17. Report No. NIER-RP2016-190.

Schmidt M, Themann A, Drexler C, Bayer M, Lanzer G, Menichetti E, et al. Blood donor screening for parvovirus B19 in Germany and Austria. Transfusion. 2007. 47: 1775-1782.

Schwarz TF, Roggendorf M, Deinhardt F. Human parvovirus B19: ELISA and Immunobolt assays. J Virol Methods. 1988. 20: 155 $-168$

Sevall JS, ritenhous J, Peter JB. Laboratory diagnosis of parvovirus B19 infection. J Clin Lab Anal. 1992. 6: 171-175.

Sewell DL. Laboratory-associated infections and biosafety. Clin Microbiol Rev.1995. 8: 389-405.

Smith CJ, Osborn AM. Advantages and limitations of quantative PCR (Q-PCR)-based approaches in microbial ecology. FEMS Microbiol Ecol. 2009. 67: 6-20.

Nagai K, Horita N, Yamamoto M, Tsukahara T, Nagakura H, Tashiro $\mathrm{K}$, et al., Diagnostic test accuracy of loop-mediated isothermal amplification assay for mycobacterium tuberculosis: systematic review and meta-analysis. Sci Rep. 2016. 6: 39090.

White DG, Woolf AD, Mortimer PP, Cohen BJ, Blake DR, Bacon PA. Human parvovirus arthropathy. Lancet. 1985. 1: 419-421.

Yamakawa Y, Oka H, Hori S, Arai T, Izumi R. Detection of human parvovirus B19 DNA by nested polymerase chain reaction. Obstet Gynecol. 1995. 86: 126-129. 
https://doi.org/10.15616/BSL.2018.24.4.390

Cite this article as: Cho KB. Development of Nested PCR Primer Set for the Specific and Highly Sensitive Detection of Human Parvovirus B19. Biomedical Science Letters. 2018. 24: 390-397. 